\title{
DA EXIBIÇÃO DOS FILMES DA COMISSÃo RONDON
}

\begin{abstract}
Ana Lobato*
Resumo: Este trabalho trata da exibição dos filmes realizados pela Comissão Rondon, dirigidos por Luiz Thomaz Reis, entre 1912 e 1938, enfocando o circuito em que os filmes foram exibidos - tanto aquele constituído por salas comerciais quanto o que diz respeito aos eventos de caráter político-científico -, o público alcançado, destacando-se ainda as estratégias mobilizadas visando à otimização desse processo. Thomaz Reis.

Palavras-chave: documentário, exibição, filmes da Comissão Rondon, Luiz

Resumen: Este trabajo trata de la proyección de los filmes realizados por la Comisión Rondon, dirigidos por Luiz Thomas Reis, entre 1912 y 1938, enfocando el circuito en el que tales películas fueron exhibidas -tanto el constituido por salas comerciales como el relativo a actos de carácter político-científico- y el público alcanzado. Se destacan, además, las estrategias movilizadas con vistas a la optimización de ese proceso. Thomaz Reis.

Palabras clave: documental, exhibición, filmes de la Comisión Rondon, Luiz
\end{abstract}

Abstract: This paper deals with the exhibition of films made by the Rondon Comission, directed by Luiz Thomaz Reis, between 1912 and 1938, focusing on the circuit in which the films were shown - consisting both on commercial exhibitions, in the theaters, as well as at political and scientific events - , the audience reached, and the mobilized strategies aiming to optimize this process.

Keywords: documentary, exhibition, Comissão Rondon's films, Luiz Thomaz Reis.

Résumé: Ce travail porte sur la projection des films produits par la Commission Rondon, réalisés par Luiz Thomaz Reis, entre 1912 et 1938, mettant l'accent sur le circuit où les films ont été présentés - aussi bien le circuit de salles commerciales que celui concernant les événements à caractère politique et scientifique -, sur le public atteint et sur les stratégies déployées visant l'optimisation de ce processus. Thomaz Reis.

Mots-clés: documentaire, projection, films de la Comission de Rondon, Luiz

* Universidade Federal do Pará - UFPA, Instituto de Ciências da Arte - ICA, Curso de Cinema e Audiovisual. 66075-110, Belém, Brasil. Email: analobatoazevedo@gmail.com

Submissão do artigo: 29 de maio de 2015. Notificação de aceitação: 20 de agosto de 2015 . 
Da exibição dos filmes...

\section{Filmes para serem vistos}

A historiografia clássica não dirigiu sua atenção para a exibição dos filmes no Brasil, o que levou Jean-Claude Bernardet a atribuir a inexistência de uma história da exibição, a uma "profissão de fé ideológica", que privilegiou a produção em detrimento da exibição, momento que inclusive é erigido como marco do "nascimento" do cinema brasileiro, por diversos autores que trataram dos primeiros tempos (Bernardet, 1995: 26). Em várias outras cinematografias a situação é distinta, destacando-se o caso clássico da França, no qual o evento tido como fundador do próprio cinema é uma "sessão pública, paga e com êxito" realizada em Paris, no Grand Café, em 28 de dezembro de 1895. (Bernardet, 1995: 25).

Este trabalho tem como foco justamente essa etapa final da trajetória das produções fílmicas, que tem sido deixada à sombra nas pesquisas relativas à história do cinema brasileiro, concentrando-se na exibição e no contato com o público dos filmes produzidos pela Comissão Rondon (CR), como ficaram conhecidas diversas comissões e órgãos chefiados por Cândido Mariano da Silva Rondon nas primeiras décadas do século XX. ${ }^{1}$ Seu objetivo é traçar um panorama da chegada desses filmes ao circuito exibidor, destacando-se aqueles que chegaram às telas dos cinemas, com que intensidade isso se deu, qual o número de espectadores alcançados, tratando ainda dos diferentes momentos desse processo e das estratégias utilizadas com vistas à difusão dos filmes.

Há referências a dezessete filmes produzidos pela $\mathrm{CR}$, realizados entre 1912 e 1938, os quais foram em sua quase totalidade dirigidos pelo Major Luiz Thomaz Reis, ${ }^{2}$ chefe da Seção de Fotografia e Cinematografia

\footnotetext{
${ }^{1} \mathrm{O}$ próprio Rondon faz menção a essa denominação em relatório encaminhado ao DASP, datado de 1943, referindo-se a “...várias repartições denominadas vulgarmente 'ComissõesRondon' " (Lasmar, 2008: 33). Para maiores informações a respeito da Comissão Rondon remeto a LASMAR, 2008 e LOBATO, 2011.

2 Os sertões de Mato Grosso (1912-1913); Expedição Roosevelt-Rondon (1913-1914); Mato Grosso em revista (1916); Rituais e festas Bororo (1916); Indústria da borracha em
} 
da $\mathrm{CR}^{3}$. Cinco desses filmes foram lançados comercialmente - Os sertões de Mato Grosso, Expedição Roosevelt, De Santa Cruz, Operações de guerra e Ao redor do Brasil -, e alguns deles também exibidos em programações de caráter político-científico.

Isso significa que aproximadamente $30 \%$ dessa produção chegou às salas comerciais. Embora a exibição dos filmes realizados pela $\mathrm{CR}$ tenha se dado de forma desigual, é importante ressaltar que tal empreitada foi bastante eficiente no que diz respeito à colocação de determinados títulos no circuito exibidor, gerando resultados altamente positivos, como se verá a seguir. Houve um significativo investimento na difusão de certos filmes, o que acarretou numa série de ações, assumidas, principalmente, pelo Major Reis, que se coloca à frente não só da realização dos filmes - envolvido com direção, fotografia e montagem - como articula iniciativas visando sua difusão. Dessa atividade, o Major Reis presta contas a seus superiores através de relatórios, ${ }^{4}$ nos quais menciona as cidades em que os filmes foram exibidos, rendas obtidas nas projeções, percentuais que consegue negociar com os empresários, relatórios esses que se constituíram em fontes fundamentais para a elaboração deste trabalho. ${ }^{5}$

Pode-se perceber tanto nos relatórios de Thomaz Reis, quanto em outros documentos e publicações da CR, em especial aquelas assinadas por Amilcar Armando Botelho de Magalhães, que assume em 1915 a chefia do Escritório Central, o firme propósito não só de realizar uma extensa

Mato Grosso e no Amazonas (1917); Wilderness/De Santa Cruz (1918); Inspeção ao Nordeste (1922); Ronuro, selvas do Xingu (1924); Operações de guerra (1924-1925); Parimã, fronteiras do Brasil (1927); Viagem ao Roraimã (1927); No rio Içana (1928); Mato Grosso e Paraná: fronteiras com o Paraguai e Argentina (1930-1931); Posto Alves de Barros (1930); Ao redor do Brasil (1932); Os Carajás (1932); Inspetoria Especial de Fronteiras (1938). Dentre esses filmes, apenas No rio Içana foi dirigido por José Louro.

${ }^{3}$ A grafia original é Seção de Photographia e Cinematographia. Utilizarei neste texto a grafia adotada nos dias de hoje, visando à fluência do mesmo. Entretanto, em casos de citação, os textos serão transcritos em sua grafia original.

${ }^{4}$ Os filmes a respeito dos quais há informações mais detalhadas nos relatórios de Thomaz Reis são Os sertões de Mato Grosso e Wilderness.

5 Os relatórios apresentados pelo Major Thomaz Reis a seu chefe imediato, Amilcar Armando Botelho de Magalhães, fazem parte do acervo do Museu do Índio. 
cobertura fotográfica e cinematográfica das ações da instituição, como também de exibir os filmes produzidos.

A CR, na pessoa de seu dirigente Cândido Mariano da Silva Rondon, atribuía enorme valor à produção imagética, a qual se destinava a finalidades diversas, como servir de fonte para pesquisas científicas e divulgar o trabalho que realizava, prestando contas à sociedade de suas atividades, contribuindo assim para o seu fortalecimento. Além disso, tais registros imagéticos permitiriam que a população fosse transportada aos locais mais longínquos e inóspitos do interior brasileiro, conhecendo suas diferentes regiões e os povos que nela habitavam. Quando Botelho de Magalhães (Magalhães, 1930: 373) destaca a possibilidade de levar as pessoas a conhecerem o "sertão" sem que precisassem se expor aos incômodos a que estariam sujeitas ao para lá se deslocarem fisicamente, aponta, indiscutivelmente, para o encontro dos filmes com o público. Em consonância com tais objetivos, a CR investe tanto na produção dos filmes quanto em sua exibição.

\section{$O$ vigor dos primeiros anos}

A primeira produção cinematográfica realizada pela $\mathrm{CR}$ convida o espectador a embarcar para Os sertões de Mato Grosso. Nesse filme inaugural a $\mathrm{CR}$ realiza plenamente os fins pretendidos, é ele que percorre o circuito mais extenso, sendo exibido em todas as regiões do Brasil, atingindo um público significativo.

Entre outubro de 1915 e março 1916, o filme circulou pelos estados do Rio de Janeiro, São Paulo e Minas Gerais. No Rio de Janeiro, chegou às telas de cinco cidades e da capital, atingindo nesta última um público de 20.000 espectadores. Na então capital da República, destacam-se as exibições de caráter político-científico realizadas em evento promovido pela Sociedade de Geografia do Rio de Janeiro no Teatro Fênix, nos dias 5, 7 e 
9/10/1915, após conferência de Rondon. Ainda no mês de outubro, o filme chegou a duas importantes salas de cinema cariocas, ${ }^{6}$ ficando em cartaz durante oito dias, no período de 18 a 27/10/1915.

No estado de São Paulo, Os sertões foi exibido comercialmente em quarenta e três cidades, entre as quais a capital, tendo sido visto, nesta última, por 15.360 pessoas, através de sessões realizadas em nove cinemas ${ }^{7}$, por um período de onze dias, entre 8/11/1915 e 12/2/1916 (Bernardet, 1979). Em Minas Gerais, chegou a três cidades, entre as quais não estava incluída, naquele momento, a capital. Nesse circuito, percorrido pelo próprio Thomaz Reis, o filme atingiu um público de 65.788 espectadores. ${ }^{8}$

Finda essa primeira etapa, o inspetor Frederico Ortiz do Rego Barros entra em cena, encarregando-se de levar Os sertões a outras cidades dos estados do Rio de Janeiro, São Paulo e Minas Gerais, bem como ao Norte do Brasil, começando pelo Estado do Amazonas, em agosto de 1916, de onde segue para o Pará. Em março de 1917, Rego Barros cuida da exibição do filme nos estados da região Sul - Paraná, Santa Catarina e Rio Grande do Sul. No relatório em que dá conta desse percurso, há ainda menção à sua exibição nos estados da Bahia, Alagoas, Pernambuco, Paraíba, Rio Grande do Norte, Ceará, Maranhão. Nos estados das regiões Sul, Norte e Nordeste, as exibições concentraram-se nas capitais.

Por ocasião de algumas sessões de $O$ sertões, caso das realizadas no Teatro Fênix, foi também incluído, como parte da programação, o filme Expedição Roosevelt, fruto da expedição científica liderada pelo expresidente norte-americano Theodore Roosevelt, entre dezembro de 1913 e

\footnotetext{
${ }^{6}$ Cinemas Palais e Pathé.

${ }^{7}$ Cinemas Íris, Pathé, Coliseu, Colombo, Guarani, Teatro Brasil, São Paulo, Rio Branco, Celso Garcia.

${ }^{8} \mathrm{O}$ relatório de Thomaz Reis, encaminhado ao Chefe do Escritório Central da CLTEMGA, que trata das atividades realizadas de outubro de 1915 a março de 1916, fornece dados detalhados a respeito desse primeiro circuito, informando as cidades em que o filme foi exibido, número de espectadores, bem como renda arrecada em cada uma delas (Reis, 1916).
} 
janeiro de 1914, guiada por Rondon e que percorreu o interior do Mato Grosso. Tal expedição foi acompanhada, durante parte de seu trajeto, por Thomaz Reis, que em determinado momento, insatisfeito com as condições de filmagem, dela se desligou, referindo-se ao resultado como "incompleto [...] devido à pressa da viagem" (Magalhães, 1930: 375). A precariedade do filme, apontada pelo próprio realizador, certamente não contribuiu para que Expedição Roosevelt tivesse uma carreira tão profícua como Os sertões. De todo modo, além das projeções mencionadas acima, foi exibido em duas salas da cidade de São Paulo, em Manaus, bem como em alguns outras cidades, juntamente com Os sertões, sendo difícil, entretanto, precisar quando isso efetivamente aconteceu, pois muitas vezes as matérias publicadas nos jornais são ambíguas, falando-se ora em filmes, ora apenas no filme Os sertões.

Ao longo dos anos 1915, 1916 e 1917 a CR cuida com afinco da exibição de Os sertões. O filme atinge um público expressivo e pelo que se pode deduzir da prestação de contas apresentada por Thomaz Reis nos relatórios em que trata desse assunto ${ }^{9}$, gerou uma renda significativa, revertida em prol das populações indígenas, dos flagelados da seca, sendo ainda utilizada para cobrir custos de produção e amortizar adiantamentos. Embora tais fatores indiquem terem sido expressivos os rendimentos gerados pelo filme, não é possível avaliar seu real significado, considerando tratar-se de moeda distinta da atualmente em circulação, e de outro contexto econômico ${ }^{10}$. Thomaz Reis fornece-nos um parâmetro nesse sentido,

\footnotetext{
9 Thomaz Reis trata do circuito de exibição de Os sertões nos relatórios relativos às atividades executas no período de outubro de 1915 a março de 1916 (Reis, 1916) e de outubro de 1916 a março 1917 (Reis, 2008). Menciona também as exibições dos filmes Expedição Roosevelt e Mato Grosso em revista.

10 Para auferir a real expressão dos valores arrecadados com a exibição do filme, seria necessário ir muito além da conversão da moeda em circulação no momento, para reais, buscando-se ainda referências relativas a custos de equipamentos, película, gastos de produção à época, procurando equivalências com os dias de hoje, tarefa que não será contemplada neste trabalho.
} 
mencionando que a exibição dos filmes ${ }^{11}$ nos teatros brasileiros gerou uma renda de dez mil dólares. (Reis, 2011: 267).

\section{Estratégias de difusão}

O divórcio entre produção e exibição, que levaria os filmes brasileiros a enfrentarem profundas dificuldades para chegar às telas dos cinemas, provocando o fim da Bela Época (1907 a 1911), considerada por alguns autores a fase áurea do cinema brasileiro $^{12}$, não impediu que $O s$ sertões de Mato Grosso fizesse uma carreira de sucesso Brasil afora. O que teria possibilitado esse estado de coisas?

Acredito que grande parte do sucesso de Os sertões, no que concerne à sua trajetória no circuito comercial de exibição, bem como de outros filmes da CR, se deve, em grande medida, às estratégias desenvolvidas com esse fim, que, devem ser creditadas, sobretudo, à pessoa de Thomaz Reis. Profissional múltiplo, extremamente habilidoso em diversas áreas da produção audiovisual, é também um homem de produção, que se envolve com questões relativas à circulação dos filmes, o que faz com tenacidade e criatividade, tirando partido das articulações possibilitadas pela instituição a qual está vinculado, o Exército.

Assim, é o próprio Thomaz Reis quem percorre o circuito inicial em que Os sertões foi exibido, composto por diversas cidades de São Paulo, Rio de Janeiro e Minas Gerais; para isso se dirigia ao local em que pretendia

\footnotetext{
${ }^{11} \mathrm{O}$ uso do plural significa que Reis se refere a Os sertões e Expedição Roosevelt, embora, como já apontei, as exibições deste último tenham sido bem mais limitadas.

${ }^{12}$ A caracterização desse período do cinema brasileiro como Bela Época, com produção intensa e a chegada dos filmes ao circuito exibidor, foi proposta por Vicente de Paula Araújo em seu livro A Bela Época do cinema brasileiro, São Paulo: Editora Perspectiva, 1976. Paulo Emilio Salles Gomes adere a essa visão em sua periodização do cinema brasileiro, proposta no "Panorama do Cinema Brasileiro: 1986/1966", publicado em Cinema: trajetória no subdesenvolvimento, Rio de Janeiro: Paz e Terra: Embrafilme, 1980. Tal compreensão a respeito desses primeiros anos do cinema brasileiro é questionada por Jean-Claude Bernardet, bem como a periodização proposta por Paulo Emílio (Bernardet, 1995: 34-48).
} 
exibir o filme, onde procurava potenciais exibidores e negociava os termos que regeriam a transação. A inexistência da figura do distribuidor possibilitava que a $\mathrm{CR}$, enquanto produtora, auferisse um percentual mais elevado do valor arrecado, dividido entre este e o exibidor, e que se situava entre $40 \%$ e $60 \%$ da renda líquida do filme ${ }^{13}$. Além disso, evitava-se a falta de controle sobre o número de espectadores e os rendimentos alcançados, bem como o desaparecimento de cópias, histórias que abundam nos primeiros anos do cinema brasileiro.

Com relação à forma como transcorriam as exibições, Thomaz Reis se encarregava de revisar as cópias, podendo realizar pequenos reparos caso necessário. A partir de certo momento, passa a contar com um assistente, que se responsabilizava pela revisão da película, garantindo assim sua integridade e a qualidade das sessões. É importante mencionar que Thomaz Reis se deslocava de uma cidade para outra, fazendo longos percursos, de modo que a cópia (é provável que viajasse com mais de uma) era intensamente utilizada, necessitando de frequentes revisões, e de uma manipulação adequada a fim de evitar maiores desgastes.

As longas viagens de Reis tinham objetivos diversos, de modo a otimizar suas ações. A caminho de uma filmagem, fazia escalas, desvios com o intuito de realizar outras atividades, procedimento esse que era rotineiro, podendo-se mapear em seus relatórios muitas situações desse tipo. No período em que se dedicava às filmagens entre os índios Bororo, que resultaram no filme Rituais e festas Bororo, cuidava também da promoção e lançamento de Os sertões no estado de Mato Grosso. Quando da exibição desse primeiro filme da CR nas cidades de Corumbá e Cuiabá, roda Mato Grosso em revista, filme realizado como uma espécie de satisfação à

\footnotetext{
${ }^{13}$ No relatório relativo ao período de outubro de 1915 a março de 1916 Thomaz Reis menciona que a renda no circuito tratado variou de $40 \%$ a 60\% (Reis, 1916). Com relação à exibição do filme em Corumbá, se detém em suas negociações com o empresário Sr. Fontanillas, que resultaram na obtenção de um percentual de 60\%, ficando sob responsabilidade da CR os custos com a música (Reis, 2008: 213).
} 
população do estado de Mato Grosso, a fim de compensar certo mal-estar face ao universo abordado em Os sertões, e mostrar à população do Rio de Janeiro que no estado havia algo além da "vida natural e selvagem". Apesar da promessa de Reis de que o filme seria levado ao Rio de Janeiro e São Paulo, suas exibições se restringiram às cidades de Corumbá e Cuiabá, onde as filmagens foram realizadas.

Ainda com o intuito de otimizar os recursos de que dispunha, Thomaz Reis recorre à estrutura da instituição a qual está vinculado, o Exército, que muitas vezes lhe fornece hospedagem durante suas viagens, em outras, se encarrega, através de seu pessoal, da execução de números musicais durante as projeções ${ }^{14}$.

Essa forma de atuação certamente contribuiu para o amplo lançamento de Os sertões, já que os recursos da instituição, sempre reduzidos, eram aproveitados ao máximo, gerando resultados diversos, num mesmo período, em decorrência da realização de atividades paralelas.

\section{A investida no mercado norte-americano}

O trabalho realizado nesses primeiros anos da Seção de Fotografia e Cinematografia da CR aponta para a existência de uma ótima infraestrutura para que o mesmo fosse realizado, com equipamentos de qualidade, bem como verba para custear deslocamentos e outras necessidades. É importante salientar, entretanto, que Botelho de Magalhães, em relatório sobre o trabalho da Seção do ano de 1916, encaminhado a Rondon em fevereiro de 1918, já pedia sua extinção "por falta de numerário". Acredito que tal solicitação revele que, apesar de bem aparelhada em seus primórdios, a Seção de Fotografia e Cinematografia esteve sob constante ameaça,

\footnotetext{
14 A propósito da exibição de Os sertões de Mato Grosso em Cuiabá, Thomaz Reis menciona que as "musicas [foram] oferecidas pelo Batalhão Policial e pelo QuartelGeneral” (Reis, 2008: 227).
} 
havendo setores no interior da CR que não apoiavam suas atividades, alvo de frequentes pressões, aplacadas pela intervenção de Botelho de Magalhães e o apoio de Rondon.

Apesar desse quadro, parte da renda de Os sertões foi revertida para as populações indígenas bem como para os flagelados da seca, sendo apenas um percentual da mesma utilizado para amortizar alguns gastos de produção e custear ações visando à exibição do filme, não permitindo que aquele serviço se capitalizasse, continuando a depender inteiramente de verba proveniente da $\mathrm{CR}$ e dos diferentes ministérios ao qual esteve vinculada. É provável que o montante arrecadado não fosse suficiente para a manutenção dos equipamentos de filmagem, do laboratório para revelação dos filmes e feitura de cópias, bem como para a aquisição sistemática de película e de outros materiais, embora pudesse minimizar essa situação de dependência. Acredito que a maneira como foram utilizados os rendimentos do filme, escapando a uma lógica de viés predominantemente econômico, possa ser atribuída a razões políticas, visando chamar atenção para a importância do trabalho realizado pela Seção e fortalecê-lo aos olhos do público e do aparelho de Estado.

O fato é que em 1919 a carência já anunciada chega a um ponto crítico, exposto por Thomaz Reis em seu memorando de 1919, encaminhado a Rondon, em que aborda a venda dos equipamentos, incluindo "material de campo e oficinas", por questões de economia, restando apenas uma câmera alemã frágil e que se encontrava inutilizada.

Nesse contexto é que se dá a viagem de Reis a Nova York, em 1918, abordada em relatório bem escrito, minucioso e espirituoso, através do qual se pode tomar conhecimento das ambições da CR e, especificamente, de Thomaz Reis, de distribuir internacionalmente os filmes produzidos pela instituição, bem como do aprendizado ao qual se debruça de forma aplicada, a fim de entender os meandros da distribuição e exibição de filmes nos Estados Unidos. Nesse relatório, Reis menciona que o objetivo da viagem 
era "exibir o filme da nossa Comissão", como também "angariar donativos para o serviço de pacificação dos nossos silvícolas" (Reis, 2011: 255, grifos meus). Embora Reis fale em donativos, o que se pode depreender de suas ações durante a viagem é a tentativa de negociar os filmes da CR no mercado norte-americano e em outros mercados internacionais, com o objetivo de gerar recursos através da exploração dos mesmos.

Voltando ao trecho do relatório de Thomaz Reis destacado acima, observa-se a menção à exibição de um filme, em outros momentos, entretanto, encontra-se referência à exibição de filmes da CR, ou ainda do filme Os sertões, o que ocorre no ofício que encaminha o relatório em questão ao chefe do Escritório Central da CR, Botelho de Magalhães. Já no relatório propriamente dito, Reis se refere a um programa em seis partes intitulado Wilderness: "1 ${ }^{\mathrm{a}}$ parte - RJ e SP; $2^{\mathrm{a}}$ parte - Expedição Roosevelt; $3^{\mathrm{a}}$ parte - índios Pareci, jogo de bola etc.; $5^{\mathrm{a}}$ e $6^{\mathrm{a}}$ parte - Índios Coroado" (Reis, 2011: 278). ${ }^{15}$

Afinal, que filme estaria sendo levado aos Estados Unidos? Trata-se de um filme ou de alguns filmes da Comissão Rondon? Tal oscilação não se constitui, certamente, em simples erro, considerando-se o esmero com que eram escritos os relatórios de Thomaz Reis. A compreensão dessa situação, do que está por trás dessa aparente confusão, nos remete à genealogia do filme Wilderness, seu processo criativo e trajetória, lançando luz ao conhecimento do tipo de cinema realizado por Thomaz Reis, e de sua atuação a fim de conquistar o mercado norte-americano.

Acredito que uma pista importante, nesse sentido, seja a categoria "programa", encontrada em vários relatórios de Thomaz Reis. Neles, "programa" não diz respeito a uma programação composta por vários

${ }^{15}$ Como se pode observar, Thomaz Reis não menciona o conteúdo da $4^{\mathrm{a}}$ parte. Denise Lasmar também se refere ao fato de Wildernes ser composto por seis partes, as quais, entretanto, apresentam algumas diferenças, sendo elas: "o ritual Bororo, caçada à onça no Pantanal, vistas do 'salto Iguassú', Rio de Janeiro e SP, Expedição Roosevelt e jogo de bola dos índios Pareci” (Lasmar, 2088: 105) 
filmes, mas a um produto específico, que normalmente designaríamos hoje como um filme. No caso das realizações de Thomaz Reis, entretanto, tais filmes ou "programas" não têm um caráter fechado, podendo ser remontados, rearticulados em função dos contextos de exibição. É isso que se pode deduzir da forma como é tratada a produção que Reis pretende exibir nos Estados Unidos. Tal possibilidade de remontagem é favorecida pelo tipo de trabalho desenvolvido por Thomaz Reis, que, como bem chama atenção Samuel Paiva, em texto sobre o filme Ao redor do Brasil, apresenta certa unidade, decorrente de uma "reiteração temática e formal" (Paiva, 2006: 231). É como se toda sua produção se resumisse a um só filme, sobre uma longa viagem pelo interior do Brasil (Lobato, 2011: 178).

O programa Wilderness é efetivamente (re)montado em Nova York; Reis viajara preparado para isso, já que levava consigo uma caixa de filmes contendo positivos e negativos. Ao planejar a viagem, filma cenas que seriam incorporadas ao "programa" a ser exibido em Nova York, como as relativas ao Rio de Janeiro e São Paulo, que não foram incluídas nos outros filmes da CR. Tais cenas tampouco seriam incluídas na versão do filme exibida no Brasil, intitulada De Santa Cruz, de acordo com sua descrição nos anúncios publicados nos jornais da cidade de São Paulo (Bernardet, 1979). As alterações feitas no filme que levava consigo, ou talvez seja mais apropriado falar na (re)montagem do material que vinha filmando ao longo de alguns anos, visavam adequá-lo à exibição nos Estados Unidos e aos futuros negócios com as empresas de exibição e distribuição do país, buscando satisfazer as exigências daquele mercado e o gosto do público norte-americano.

Chegando a Nova York, Thomaz Reis procura o ex-presidente americano Theodore Roosevelt, em nome de Rondon, a quem pede ajuda para exibição do filme da CR na cidade. Reis sugere a Roosevelt a realização de uma "função solene", para a qual seriam convidados “elementos oficiais" e a imprensa, com objetivo de atrair empresários das 
casas de exibição (Reis, 2011: 267). O programa Wilderness é exibido no Carnegie Hall, de Nova York, com casa lotada (2.800 lugares), após conferência do ex-presidente Roosevelt, em 15/5/1918, sob os auspícios da Sociedade Americana de Geografia. Thomaz Reis aproveita a magnitude dessa sessão, convidando representantes das "companhias principais de filmes", tendo comparecido à mesma "os chefes da Metro, Paramount, National, Interocean, Fox, Educational Goldwin, World" (Reis, 2011: 278).

Esse grandioso e bem sucedido evento foi preparado de forma cuidadosa, Thomaz Reis se dedicou a estudar o mercado cinematográfico norte-americano, com preocupações que iam desde o gosto do público, até questões ligadas ao circuito distribuidor e exibidor, investigando quais as empresas confiáveis e adequadas ao tipo de cinema realizado pela CR. Para isso, faz sessões prévias, a partir das quais percebe que algumas adaptações deveriam ser feitas no filme que estava (re)construindo. Assim, faz cortes em função da censura, com eliminação de cenas em que os índios estão nus e as tomadas são próximas; elabora intertítulos em inglês, com a contribuição da jornalista Lilian Elliot, que possuía um livro escrito sobre o Brasil e havia viajado pela América do Sul. Os títulos relativos à parte dos índios Pareci e Nhambiquara foram traduzidos do livro do Coronel Roosevelt, "a fim de dar interesse quanto ao ponto de vista americano" (Reis, 2011: 271).

Com relação ao gosto do público, merecem destaque os perspicazes e irônicos comentários de Reis, cuja percepção decorreu de contatos feitos por ele com o objetivo de conseguir a publicação, naquele país, do livro de Conferências de Rondon. Com a palavra Thomaz Reis:

Deveria ter um certo número de fotografias nítidas, sobre animais ferozes, índios, etc., e que quanto possível alguma cousa sensacional, por exemplo, o Coronel Rondon lutando com um tigre ou um colossal sucuri dominando um chefe Coroado em presença da tribo espavorida atirando-lhe 
flechas, depois tudo isto arrastado pelo Salto Belo e precipitado na queda onde deveria aparecer algum americano forte como George Walsh e salvar tudo, exclamando "Liberty", foi o que eu imaginei pudesse ser o estilo mais apreciado ali. (Reis, 2011: 259).

Ainda com o intuito de garantir a realização de um evento de alto nível, e exibir um filme capaz de agradar o público em geral e, em particular os representantes das salas de exibição e empresas de distribuição, Thomaz Reis cria condições para produzir os materiais necessários e não subsidiados pela Sociedade Americana de Geografia, que se responsabilizara pelos custos com o Carnegie Hall. Administrando a reduzida verba de que dispunha, Thomaz Reis se encarrega da impressão dos programas para a sessão, bem como de contratar a orquestra para a execução dos números musicais, recorrendo a músicos pertencentes aos regimentos militares, que se dispuseram a trabalhar por um preço mais em conta do que o praticado por músicos profissionais. Reis se encarrega da escolha das músicas a serem tocadas, definindo o momento em que deveriam ser executadas, e para que isso acontecesse de forma precisa, desenvolve um método de sinalização para os músicos, fazendo as vezes de maestro.

Apesar do sucesso da exibição de Wilderness no Carnegie Hall, a imprensa nova-iorquina manteve total silêncio a respeito do filme, não colaborando com sua divulgação e circulação na cidade, onde o filme ainda permaneceu em cartaz, no Teatro Strand, por oito dias. De acordo com Reis, afluiu um público bastante expressivo a tais sessões no Strand, importante cinema da Broadway, embora o verão já estivesse iniciando, o que afastava a população nova-iorquina das salas de cinema.

Depois de muitas idas e vindas, de possibilidades frustradas por razões variadas, entre as quais a falta de idoneidade de uma companhia com a qual estava prestes a fechar negócio, Reis assina um contrato para distribuição da produção cinematográfica da $\mathrm{CR}$ no mercado internacional 
com a empresa Interocean, o que, entretanto, não dá resultados positivos, tendo sido rescindido após dois anos (Bernardet, 1979). A viagem de Reis aos Estados Unidos, muito bem sucedida de certo ponto de vista, com a exibição de Wilderness numa das mais importantes casas de espetáculo de Nova York, o Carnegie Hall, bem como numa sala de cinema de primeira linha, o Strand, não foi capaz de produzir os resultados econômicos esperados.

Depois da experiência nova-iorquina, o filme circularia apenas no Brasil: na cidade de São Paulo onde foi exibido em doze cinemas da capital $^{16}$, bem como em Santos e Campinas, entre agosto e setembro de 1920, tendo atingido um público de 20.677 espectadores (Bernardet, 1979). Chegou também às telas de nove cinemas da cidade do Rio de Janeiro, ${ }^{17}$ durante vinte dias, no período de 11/10/1920 a 8/11/1920.

\section{Nos anos seguintes}

Apesar das dificuldades econômicas e técnicas enfrentadas pela Seção de Fotografia e Cinematografia da CR no final de 1919, Thomaz Reis propõe a feitura de um filme para os festejos do Centenário da Independência em 1922, lembrando que para isso seria necessário adquirir novo equipamento. O projeto, extremamente ambicioso, no qual pretendia abordar o Brasil do ponto de vista de sua fauna, flora, geologia, bem como os usos e costumes de suas populações indígenas, a ser feito em duas partes, não se concretiza (Reis, 1919). Cerca de dez anos depois, Thomaz Reis realiza Ao redor do Brasil, filme que dialoga com esse projeto não executado, e parece ter sido o filme possível, construído a partir de trechos de diversos outros trabalhos por ele realizados. Esse será o último filme da

${ }^{16}$ Cinemas Avenida, Central, Pathé, Colombo, São Paulo, São Pedro, Royal, Rio Branco, Coliseu C. Elíseos, América, Brasil e Espéria.

${ }^{17}$ Cinemas Pathé, Atlântico, Centenario, Cine Theatro America, Modelo, Ideal, Meyer, Smart e Velo. 
CR a chegar ao circuito comercial, com projeções em sete salas da cidade de São Paulo ${ }^{18}$, no período de janeiro a março de 1933 , durante vinte e nove dias.

No período que se situa entre a circulação dos filmes De Santa Cruz e Ao redor do Brasil, apenas dois outros filmes produzidos pela $\mathrm{CR}$ foram exibidos em situações públicas: Ronuro, selvas do Xingu, por ocasião do Congresso de Geografia realizado em Vitória em 1926, e Operações de guerra, no Cinema Parisiense, no Rio de Janeiro, em agosto de 1926.

A não circulação de diversos filmes produzidos pela $\mathrm{CR}$, ou sua exibição em situações bem pontuais, pode ser atribuída a um conjunto de fatores, entre os quais a precariedade da Seção de Fotografia e Cinematografia da $\mathrm{CR}$, em diversos momentos de sua trajetória, como o final da década de 1920. Podem, ainda, ter concorrido para isso as características dessas produções, já que algumas delas tratam de situações muito específicas e com possibilidades mais restritas de diálogo com um público diversificado. Deve-se levar em conta, também, a forma como muitas filmagens aconteceram, gerando não apenas limitações do ponto de vista técnico, quanto no que concerne à construção da narrativa fílmica, sem que o cineasta tivesse condições e tempo necessários para a elaboração de sua obra, o que é apontado por Thomaz Reis a propósito da situação em que se deram as filmagens que redundaram em Ronuro, selvas do Xingu:

Certas viagens, a marchas forçadas, em que não se perde tempo, num "toca-toca" para a frente, são um verdadeiro martyrio para o artista, que não tem oportunidade de repousar o sentimento, para melhor coordenar os elementos de seu trabalho. Não sou amigo das viagens de urgencia, quando ha um objetivo de arte a obter. (Magalhães, 1930: 376).

\footnotetext{
${ }^{18}$ Cinemas Odeón, São Bento, Santa Cecília, Mafalda, Braz Politeama, Capitólio e Central.
} 
Nem sempre foi possível harmonizar o trabalho da CR com as demandas da produção artística, e, como observa Botelho de Magalhães, em determinadas circunstâncias o serviço cinematográfico acabou secundarizado (Magalhães, 1930: 376). Em diversas ocasiões, por razões distintas, Reis se ressentiu com as limitações impostas a suas possibilidades criativas, e consequentemente à realização de outros filmes com a qualidade artística desejada, e potencial para chegar a um público mais amplo. Apesar da compreensão dos membros da $\mathrm{CR}$ e, em particular, de Botelho de Magalhães e Rondon quanto à importância do trabalho cinematográfico de Thomaz Reis, não havia como superar inteiramente as demandas da instituição, suas prioridades e ritmos.

\section{Da divulgação dos filmes}

Os filmes realizados pela CR e lançados comercialmente foram intensamente divulgados, seja através de anúncios publicados em jornais de grande circulação, como através de matérias, frequentes, sobretudo nos jornais de cidades do interior dos estados de São Paulo, Rio de Janeiro, Minas Gerias e Mato Grosso, por ocasião da exibição de Os sertões, bem como nos jornais das capitais dos outros estados nos quais o filme circulou $^{19}$. Thomaz Reis tem um papel central nesse trabalho de divulgação, embora, em várias ocasiões sua posição de diretor não seja explicitada, sendo-lhe atribuída, por exemplo, a função de "hábil operador" (Commercio de Jahu, Jahu, 29/10/1916), ou de ser a pessoa encarregada de levar o filme ao local em que seria projetado (Tribuna, Corumbá, 17/6/1916). De todo modo, sua presença na redação dos jornais é constantemente mencionada, municiando os jornalistas com informações sobre o filme, contando

\footnotetext{
19 Há cópias de matérias publicadas em jornais de diversas cidades brasileiras em que o filme foi exibido em pasta relativa a esse diretor, no acervo da Cinemateca Brasileira de São Paulo.
} 
histórias e aventuras vividas durante as filmagens, capazes de despertar o interesse do espectador. Tais notícias, em certos casos, começam a ser veiculadas algum tempo antes da realização das projeções e até mesmo do seu agendamento. Em várias cidades são promovidas sessões dirigidas especialmente à imprensa, e por vezes também às autoridades locais.

Tanto nas matérias tratadas acima, quanto nos anúncios publicados nos principais jornais das cidades do Rio de Janeiro e São Paulo, relativos à exibição dos filmes Os sertões de Mato Grosso, De Santa Cruz e Ao redor do Brasil, ressalta-se, logo de início, o fato de o filme abordar o "importante" e "eficaz" trabalho da Comissão Rondon. Em geral destaca-se a figura de Rondon, a estrela dos filmes, tratado sempre de forma elogiosa, como um profissional "abnegado", "valoroso", um "ilustre patrício". Um episódio ocorrido no momento em que Os sertões estava em cartaz ilustra bem o prestígio de Rondon e, consequentemente, seu potencial para atrair espectadores para os filmes. Trata-se de debate travado na Comissão de Finanças do Senado, a respeito da concessão de um crédito suplementar à CR, ocasião em que o Sr. Guanabara defende tal concessão, enumerando os feitos de Rondon, qualificando-o como "um patriota, um benemérito e um abnegado". ${ }^{20}$

Por diversas vezes, através dos textos jornalísticos, faz-se uma espécie de chamamento à "população culta", apela-se a seu "patriotismo" e "humanismo", e à sua capacidade de valorizar o "trabalho admirável de cattechese do imortal Rondon, Roosevelt do Sul, gloria do Brasil". ${ }^{21}$ Vai nesse mesmo sentido a menção ao fato de a renda dos filmes ser revertida para o fortalecimento do trabalho do Serviço de Proteção aos Índios (SPI), com a pacificação dos grupos indígenas, bem como para os flagelados da seca. Assistir aos filmes da CR se torna, assim, uma missão cívica, uma forma de contribuir para a solução de algumas questões sociais que afligem

20 "No Senado", Correio da Manhã, Rio de Janeiro, 31/10/1915, p. 2.

21 "Radium Parque", Tribuna do Norte, Pindamonhangaba, 30/03/1916. 
a sociedade brasileira de então. Tais argumentos ganham mais força, num momento em que se trava intenso debate a respeito do tratamento que deveria ser dispensado às populações indígenas, com quem as frentes de expansão, e em particular a CR, vinham se defrontando, ganhando terreno a posição assumida por Rondon em prol de um contato pacífico, recusando taxativamente o recurso à violência, a fim de levar a "civilização" às populações indígenas, incorporando-as à sociedade nacional.

Outro aspecto destacado na divulgação dos filmes é o fato de abordarem as riquezas do interior brasileiro, suas belezas, sua fauna exuberante, formada por animais de grande porte, que exigem especial destreza para serem enfrentados. Nos diversos anúncios que tratam da exibição de De Santa Cruz no Rio de Janeiro, tal aspecto é sempre referido logo após menção à Comissão Rondon e a Rondon, conforme trecho que se segue:

Conjunto cinematográfico relactando aspectos inéditos da patriotica campanha da Comissão Rondon. (...) Cinco partes em que se acompanha o Apostolato Rondon através do pantanal e a floresta, em que se verá a caçada da onça, a caça do jacaré pelos Indios, em que as selvas brasileiras se desdobram magnificentes, em que rios e cascatas são entrevistos pela Civilização, em que pela primeira vez foram cinematografados os rituais das Tribus Borôros. Tradições dos silviculas. A beleza do nosso imenso solo. ${ }^{22}$

Ainda que o cinema de Thomaz Reis se distancie do filão que se dedicou a flagrar as belezas naturais brasileiras, a exuberância de sua fauna e flora, suas magníficas cachoeiras, identificado por Paulo Emílio Salles Gomes como "berço esplêndido" (Gomes, 1986: 328), tais situações permanecem presentes em seus filmes, ele também aponta sua câmera para os aspectos grandiosos e espetaculares do interior do país, dedicando-se, por exemplo, a filmar as Cataratas do Iguaçu, investindo na filmagem da caçada

\footnotetext{
${ }^{22}$ Anúncio publicado no Correio da Manhã, Rio de Janeiro, 09/10/1920, p. 12.
} 
da onça e seu embate com o homem, situação difícil de ser registrada e à qual se dedicou com perseverança ${ }^{23}$. Entretanto, tais situações certamente não se constituem no cerne do cinema de Thomaz Reis, cujo objetivo é abordar o trabalho desenvolvido pela $\mathrm{CR}$, as populações com as quais a mesma entra em contato, em particular os grupos indígenas, como também a fauna e flora do interior do país, sua geografia, o que serviria de fonte para pesquisas científicas. O próprio Paulo Emílio distingue o trabalho de Thomaz Reis do tipo de produção que qualifica como "berço esplêndido" (Gomes, 1986: 328); vai nessa mesma direção a compreensão de Carlos Roberto de Souza quando diz que "decididamente não seriam esses os aspectos que Reis gostaria de ver revelados em seu trabalho" (Souza, 1981: 8). Embora tais aspectos estejam presentes, a ênfase dada aos mesmos soa excessiva, e acredito que possa ser compreendida como uma estratégia de divulgação, capaz de potencializar o diálogo dos filmes com o público, que vinha sendo alimentado com fartas doses de "berço esplêndido", e estimulado a demandar esse tipo de produção.

No trecho do anúncio transcrito acima, enfatiza-se, ainda, a abordagem de grupos indígenas, de seus costumes, possibilitando o contato do espectador com populações que lhe eram desconhecidas. Se tal fato, por um lado, funcionava como um atrativo, por outro, a forma de vida desses grupos, e mais especificamente sua nudez, é apontada como uma limitação à visão do filme por certos segmentos da população, como as senhoritas. Esse assunto é tratado em várias matérias, havendo aquelas que aconselham as senhoritas a se retirarem da sessão após a $5^{\mathrm{a}}$ parte, constando nesse ponto do filme uma advertência acerca do conteúdo do trecho final: "Previne-se as Exmas Familias de que na Sexta parte a seguir foram cinematografados os índios Nhambiquaras completamente nús, tal qual vivem no sertão." (Lasmar, 2008: 208). O debate sobre esse assunto é intenso, havendo

${ }^{23}$ Em um de seus relatórios se detém nas filmagens das "Cataractas do Iguassú", bem como da "caçada da onça" (Reis, 2008: 17-40). 
também aqueles que não veem problema na veiculação de tais imagens, já que "esta circunstancia do nú não implica de modo algum uma offensa moral". ${ }^{24}$

O cinema de Thomaz Reis tanto se detém na missão "civilizadora" da $\mathrm{CR}$ e as consequentes mudanças advindas desse processo, representada, por exemplo, pela doação de roupas a um grupo de índios em Ao redor do Brasil, quanto busca sua força ao flagrar os índios Bororo da forma como viviam antes do contato com o colonizador, com o intuito de transmitir ao espectador uma "perfeita e nítida impressão da Era da Descoberta do Brasil, na época de Cabral", como diz o trecho final do anúncio que vem sendo discutido. Thomaz Reis tinha consciência do quão impactantes podiam ser os costumes dos índios Bororo, bem como da importância de tais registros para estudos científicos, empenhando-se em registrar sua cultura em seu estado mais "puro" possível, evitando, as mudanças introduzidas pelo homem branco. Movimento pendular: doa-se roupas, em um momento, e em outro, pede-se aos índios que se dispam, apenas temporariamente ${ }^{25}$. Embora tais filmagens tenham acontecido em 1916, de acordo com os termos do anúncio e os valores que o sustentam, as tradições culturais registradas, em verdade, diriam respeito a um tempo pretérito, à época de Cabral, de modo que os índios Bororo e os demais povos indígenas precisariam passar por transformações, a fim de adequar seu passo, entrando em sintonia com os novos tempos.

24 “Os sertões de Matto Grosso", Gazeta de Taubaté, Taubaté, 19/2/1916.

${ }^{25}$ Sabe-se, através de relato do próprio Thomaz Reis, que o mesmo solicitou aos índios Bororo que não usassem as roupas introduzidas pelos brancos, durante as várias etapas do ritual funerário que estava filmando (Reis, 2008). 
Da exibição dos filmes...

\section{Referências bibliográficas}

BERNARDET, Jean-Claude (1979), Filmografia do Cinema Brasileiro 1900-1935: jornal O Estado de São Paulo, São Paulo: Secretaria de Cultura, Comissão de Cinema.

BERNARDET, Jean-Claude (1995), Historiografia Clássica do Cinema Brasileiro, São Paulo: Annablume.

GOMES, Paulo Emílio Salles (1986), “A experiência social dos filmes documentais no cinema mudo brasileiro (1898-1930)" in Carlos Augusto Calil e Maria Teresa Machado (eds.), Paulo Emílio: um intelectual na linha de frente, São Paulo/Rio de Janeiro: Brasiliense/Embrafilme, pp. 323-330.

LASMAR, Denise Portugal (2008), O Acervo Imagético da Comissão Rondon, Rio de Janeiro: Museu do Índio.

LOBATO, Ana (2011). "Viajando pelas fronteiras do Brasil" in Samuel Paiva e Sheila Schvarzman (eds.), Viagem ao cinema silencioso do Brasil, Rio de Janeiro: Beco do Azougue, pp. 174-191.

MAGALHÃES, Amilcar Armando Botelho (1930), Pelos sertões do Brasil, Porto Alegre: Liv. Globo.

REIS, Luiz Thomaz (2008), "Relatório apresentado pelo $2^{\circ}$ Tenente Luiz Thomas Reis ao Capitão Dr. Amilcar Botelho de Magalhães, chefe do Escriptorio Central, relativo ao período de outubro de 1916 a março de 1917" in Denise Portugal Lasmar, O acervo imagético da Comissão Rondon, Rio de Janeiro: Museu do Índio - FUNAI, pp. 210-255.

REIS, Luiz Thomaz (2011), "Relatório apresentado pelo Sr. $1^{\circ}$ Tenente Luiz Thomaz Reis da sua excursão aos Estados Unidos da América do Norte - 1918", in Samuel Paiva e Sheila Schvarzman, (eds.), Viagem ao cinema silencioso do Brasil, Rio de Janeiro: Beco do Azougue, pp. 252-287. 
RODRIGUES, João Carlos (1982), Major Luiz Thomaz Reis: o cinegrafista de Rondon, Rio de Janeiro: Departamento de Documentação e Divulgação da Embrafilme.

SOUZA, Carlos Roberto (1981). Apresentação. São Paulo: Cinemateca Brasileira, datilografado.

PAIVA, Samuel (2006), "Ao Redor do Brasil: cinema como apropriação", in Rubens Machado Jr. et al. (eds.), Estudos de Cinema Socine, VII, São Paulo: Annablume; Socine, pp. 225-231.

\section{Fontes arquivísticas}

REIS, Luiz Thomaz (1916), Supplemento $n^{o}$ 5, Relatório apresentado ao Capitão Amilcar Armando Botelho de Magalhães, Chefe do Escriptorio Central, dos trabalhos executados de outubro de 1915 a março de 1916, Rio de Janeiro: Comissão de Linhas Telegraphicas Estrategicas do Matto-Grosso ao Amazonas.

REIS, Luiz Thomaz (1919), Memorandum de Luiz Thomas Reis ao General Cândido Mariano da Silva Rondon, Rio de Janeiro: Comissão de Linhas Telegraphicas Estrategicas do Matto-Grosso ao Amazonas. 